\title{
ISSUES IN THE ASSESSMENT OF REAL-LIFE LEARNING WITH ICT
}

\author{
Anne McDougall \\ Department of Science \& Mathematics Education, The University of Melbourne, Australia \\ a.modougall@unimelb.edu.au
}

\begin{abstract}
This paper examines some aspects of the assessment of the effectiveness of learning with information and communications technologies (ICT) in real-life learning contexts, and looks at the role of ICT as a tool in assisting this endeavour. It argues that real assessment of learning with ICT is a challenging task, and that assessment strategies that are simple and economical to use need to be balanced with use of strategies that acknowledge the complexity of the learning processes and outcomes being assessed. To illustrate the case the paper draws on research work being undertaken by two groups within the Department of Science \& Mathematics Education at the University of Melbourne. The first is a group of staff and research students who are examining the learning of students in a postgraduate teacher education course on robotics. One researcher within this group is comparing the learning of novice programmers working in both syntactic and symbolic programming environments, looking at the need to take account of differences in learning styles and preferences among individuals when learning is assessed. The second group is a research team exploring novel and sophisticated uses for ICT itself as a tool in educational research, particularly in the study of the complex learning processes of groups of students. This work, initially devised for studying the learning interactions occurring in classrooms, is being adapted by another researcher in the robotics research group to study the learning by groups of adult learners of scientific concepts such as gearing.
\end{abstract}

Key words: Assessment, cognitive style, multimedia, group work, research. 


\section{INTRODUCTION}

It is widely acknowledged that assessing learning with ICT is a challenging task (Johnson et al. 1994, McDougall 2001, Harrison et al. 2002, Cox et al. 2003). Throughout the development of the use of ICT for learning extensive work has been undertaken on formative evaluation and assessment of software and of innovative projects, but no similar range of effective and reliable ways of assessing real learning gains attributable to or associated with the use of ICT has so far been developed. Nevertheless it is critically important to develop effective techniques for doing this in the light of the major developments and growing investment in ICT resources for learning, including of course real-life learning.

The difficulty of assessing real-life learning with ICT is the result of a combination of many factors. This paper will focus particularly on three of these, all of which contribute to the challenge of the task. These are: individual differences in cognitive and learning styles among learners; the complexity of what is to be assessed, and the likelihood that existing forms of assessment cannot measure all of the aspects of learning that might occur, when a learner works in a multimedia environment; and the need for assessment techniques that are more sophisticated than the traditional studyand-test approaches, in order to allow for the complexity of learners' interactions and achievements with ICT. This last is particularly important for real-life learning, where much valuable learning is undertaken in discussions with mentors of one kind or another or with groups of learners.

\section{INDIVIDUAL DIFFERENCES AMONG LEARNERS}

The matter of individual differences among learners has long been an issue in education. Current research is showing that such differences can be dramatically evident and can have a major impact on assessment in settings where ICT is used. Differences in impact on learning are being observed in case studies of students involved in exactly the same ICT activity. These are exemplified by findings from a research project investigating the effects of the use of ICT in students' writing, recently completed by John Vincent at the University of Melbourne. Although this study was undertaken with school students, it raises an issue of major importance for learning beyond school settings as well.

Vincent's project was stimulated by his earlier observation of a small number of students who had great difficulty with writing and other forms of verbal expression but showed astonishing improvement immediately on being introduced to multimedia software such as MicroWorlds. Vincent set 
writing tasks to be undertaken by his students in various ways - with pen and paper, with a word processor, and in multimedia environments. He collected the students' written work and computer files, administered a questionnaire on their attitudes to writing, made notes of observations and recorded interviews with the students. Conjecturing that in his previous work the students helped by the multimedia software appeared to have a preference for visual rather than verbal styles of working, he also administered a cognitive styles test (Riding \& Cheema 1991) to the students.

As might be expected in a mixed ability group, he found a wide range of levels of attainment in writing with pen and paper. Some students wrote freely and with high levels of complexity. Others had enormous difficulty in producing more than a few words; some of these students had been assessed as "at risk" and were receiving remedial help. Of course there were many students performing at levels between these two extremes. The wordprocessed work produced very similar results. However, given the option of using MicroWorlds for their writing, some of the students for whom the task had previously seemed almost impossible adopted the new environment with enthusiasm and produced longer and often complex pieces in which the writing was integrated in various ways with graphics, animation and sound provided by the multimedia environment. By contrast, some of the students who were highly skilled writers previously, found the requirement to use non-verbal modes inconvenient, complaining that this hindered their work and stopped the flow of their writing. Again there was a range of student responses between these extremes. For some students in the class it was strikingly clear that the multimedia environment enabled vastly enhanced performance, while for others not only was it unhelpful but it actually hindered writing activities (Vincent 2003).

Vincent's work shows some patterns that appear to relate directly to differences in cognitive styles. Since cognitive style is generally acknowledged to be robust over time for individuals, we can expect that individual variations in what is learnt, and how, will occur similarly when learners interact with ICT environments in real-life learning situations.

Assessment of performance of different learners in real-life learning situations might also depend on what kinds of ICT environments are used. Vincent's study found marked individual differences among students who were all using the same software environments - the word processor, then the multimedia environment - for the same tasks. John Murnane, also working at the University of Melbourne, is extending Vincent's work, investigating some similar issues with real-life learners, exploring the hypothesis that different types of software might be preferred by different individuals undertaking the same task. 
Murnane is working with teachers in a professional development context undertaking a Masters level subject as part of their study for a postgraduate qualification in Information Technology in Education. Within the subject Educational Programming Environments the teachers learn programming for robotics. Murnane is offering these learners two contrasting robotics programming environments. One is a word-based development of the Logo programming language. The other, RoboLab, uses a completely graphical programming system in which icons representing different elements such as motors, decisions, loop structures and containers are dragged onto the desktop and connected. Using observations and videotaped records of the teachers working, their reflective journals and the cognitive styles analysis instrument used by Vincent, Murnane is investigating how the teachers learn the programming for their robotics activities in each of these environments. $\mathrm{He}$ is comparing the ways in which the teachers react, solve problems and learn with these two environments. He is seeking any preferences individual learners might have for either environment for learning programming, reasons for such preferences, and views on each environment for the teaching of programming for robotics in schools. In particular he is investigating whether the cognitive styles of the learners are related to their use and perceptions of each environment. It is anticipated that gaining understanding of individuals' preferences might enable provision of more equitable assessment through offering students a choice of the programming environment to use.

Preliminary analysis of Murnane's data suggests that the teachers do perceive important differences in the learning experiences provided by the two environments. The assessment issues raised by Vincent apply in the setting in which Murnane is working, but at the time of writing it is too early to establish the relevance of these differences for assessment of programming for robotics and the extent to which they might relate to individual differences in the learners' cognitive styles.

\section{ASSESSING LEARNING IN MULTIMEDIA CONTEXTS}

Vincent described students, almost completely incapable of expression in words, who produced complex and sophisticated narratives when allowed to work in multimedia environments. Judged solely in verbal terms these students appeared to be severely limited in their ability to express their ideas and understandings. However the multimedia artefacts they produced dramatically belie this assessment. 
Vincent notes that almost all of the official assessment tools that teachers use are verbally based, so the performance of a learner is judged by skills with words. He used the Writing Assessment instrument of the Victorian Curriculum and Assessment Authority's Achievement Improvement Monitor (VCAA 2003) to assess his students' pieces written with pen and paper and with word processor. However he found that this instrument was completely unsatisfactory for assessing the multimedia products of his students.

Words are only one of a number of semiotic modes that are used in multimedia products. To assess the performance of a learner working in a multimedia environment it is necessary to understand the use of a range of modes, including images, sounds, music, animation, and text, in communicating what the learner intends. Each of these modes may have its own assessment techniques, and thus in a multimedia environment we are presented with a far more complex assessment task.

Vincent developed an approach to assessing the multimedia products of his students, taking account of the range of modes used, how they were used for effect, and the extent to which they were integrated in the piece. While his technique goes some way toward addressing the problem, he acknowledges that it is just a beginning and argues that much more work is needed to develop reliable and complete assessment techniques for assessing the performance of learners working in multimedia environments.

\section{ASSESSING LEARNING IN COLLABORATIVE GROUPS}

The assessment of group learning activities, like the matter of individual differences among learners, is not an issue peculiar to real-life learning. However it is particularly important in real-life learning contexts as learning through discussions and group activity are very widely used strategies in real-life learning settings.

Assessment of learning undertaken in collaborative groups is one of the issues arising in another study being undertaken in the robotics classes at the University of Melbourne. Debora Lipson is investigating the acquisition of the concepts of gears and gearing by adult learners in a constructionist robotics environment. The subjects for her study work together in small collaborative groups to build and program robots. This group work replicates a range of real-life learning situations in which groups of learners work on open-ended, authentic problem-solving tasks. An essential requirement for effective learning in such situations is good interaction with other group members; there must be clear communication among the learners in the group. How might such interactions be assessed with validity and reliability? 
Assessment might be undertaken in substantial periods of observation of each group at work, but this is rarely practicable. Lipson is using videorecording of her groups at work to enable assessment not only of the knowledge gained by the students at the end of the course but of the processes used by the groups to achieve their outcomes, the levels of discussion, and the types of interactions and learning communications within the groups as they work.

While video-recording is currently used quite widely for collecting data for research, the amount and richness of data collected this way and the time taken to analyse it makes it generally impractical for regular assessment purposes. However a technique currently being developed for video data analysis for research purposes may well be adaptable for group learning assessment purposes as well.

A novel strategy for video data analysis that enables detailed research into the interactions in classrooms has been developed by David Clarke and his colleagues at the International Centre for Classroom Research (ICCR) at the University of Melbourne. These researchers argue that studying the complexity of interactions among learners necessitates multi-faceted analysis of classroom interactions to investigate student learning; this is particularly necessary in the context of recent shifts from a view of learning as transfer to a view of learning as constructed in action (Clarke, Sahlstrom, Mitchell \& Clarke 2004).

Clarke and his colleagues use three video cameras to record classroom lesson sequences; one camera focuses on the teacher, one on the class as a whole, and the third on a small group of students. Software allows researchers to create codes for lesson events in real-time as they are happening in the classroom. Mixing of the teacher and student camera images into a split-screen video record is undertaken on-site; this can then be used to stimulate participant reconstructive accounts of classroom events. Thus the video recordings can be supplemented by post-lesson videostimulated interviews with students and teachers, as well as scanned samples of written work, and test and questionnaire data. These techniques are currently being used in a major international study of mathematics classrooms, and aspects of the ICCR strategy are assisting several smaller studies in science and ICT classroom settings.

Techniques for compression, editing, storage and transfer of digitised video and other data, and software tools for sophisticated analyses of these complex data bases have been developed by the group. This has involved working in collaboration with an Australian software company Sportstec to adapt a video analysis software product Studiocode, used in televising Australian Rules football, for use with classroom video data (Mitchell, Clarke, Sahlstrom \& Clarke 2004). Classroom events appear as coded 
instances in a timeline window and are immediately accessible as a video playlist. A matrix editor allows a researcher to view statistics on classroom events in a two-dimensional table format. Events associated with particular cells of the matrix can then be selected in any order, and a video created immediately that can play back all of these instances. Codes can also be exported into Excel spreadsheet files for further statistical analysis.

The approach is proving powerful in examining some of the more complex aspects of student learning in classroom and smaller group situations. High-ICT research techniques such as this, investigating the complex communications within groups of learners, will provide insights into group learning processes and - while I am not suggesting the use of three-camera strategies for assessment - could provide more sophisticated techniques for assessment of the work of groups and communities of learners.

\section{CONCLUSION}

The paper explores some aspects of the complexity of assessing real-life learning with ICT, focusing on three particular issues. The first is the problem of differences in cognitive styles of learners. Some aspects of this were illustrated with a description of research on school students' writing, and the extension of this work into a current study of adult learners' preferences for different software environments for programming for robotics.

The second is the problem of suitable strategies for assessing learning in multimedia environments. A pioneering attempt to address this with an assessment instrument taking into account the variety of modes of communication used in a multimedia artifact and the extent to which these modes are integrated was described.

Thirdly the paper raised the possibility that a recently developed sophisticated approach to analysis of video data, currently being used for research into learning interactions in classrooms, could be adapted to assist in the difficult but important task of assessing real-life learning in collaborative groups.

\section{REFERENCES}

Clarke, D., F. Sahlstrom, C. Mitchell \& N. Clarke (2004) Optimising the Use of Available Technology in Educational Research. Paper for presentation at the $7^{\text {th }}$ IASTED International Conference on Computers and Advanced Technology in Education CATE 2004, Hawaii. 
Cox, M., C. Abbott, M. Webb, B. Blakeley, T. Beauchamp \& V. Rhodes (2003) ICT and Attainment: A Review of the Research Literature. London: Department for Education and Skills.

Harrison, C., C. Comber, T. Fisher, K. Haw, C. Lewin, E. Lunzer, A. McFarlane, D. Mavers, P. Scrimshaw, B. Somekh \& R. Watling (2002) ImpaCT2: The Impact of Information and Communication Technologies on Pupil Learning and Attainment. A report to the DfES. ICT in Schools Research and Evaluation Series No.7. Coventry: Becta.

Johnson, D.C., M.J. Cox \& D.M. Watson (1994) Evaluating the impact of IT on pupils' achievements. Journal of Computer Assisted Learning 10, 138-156.

McDougall, A. (2001) Assessing learning with ICT. Journal of Computer Assisted Learning 17, 223-226.

Mitchell, C., N. Clarke, F. Sahlstrom \& D. Clarke (2004) Optimising the Use of Available Technology in Educational Research. Paper for presentation at the Australian Computers in Education Conference, Adelaide.

Riding, R. \& I. Cheema, (1991) Cognitive Style Analysis. Birmingham: Learning Assessment Unit.

VCAA (2003) Achievement Improvement Monitor. Melbourne: Victorian Curriculum and Assessment Authority.

Vincent, John (2003) Individual Differences, Technology and the Teacher of the Future. In McDougall, A., J. Murnane, C. Stacey \& C. Dowling (Eds.) ICT and the Teacher of the Future. Sydney: Australian Computer Society, 127-9. 